\title{
Correlation between strength and flexibility of knee flexors and extensors muscles in youth soccer players
}

\author{
Maira Peloggia Cursino', Ana Elisa Zulliani Stroppa Marques², Hugo Castellon Quatrochi , \\ Flavia Roberta Faganello Navega ${ }^{4}$, Cristiane Rodrigues Pedroni ${ }^{2}$
}

\begin{abstract}
Introduction: Soccer is the most played sport in the world and the one that causes more injuries. Imbalance between knee flexor and extensor is the main cause of muscle injuries in soccer players. Objective: The aim of this study was to verify the asymmetry and the correlation between the strength and flexibility of knee flexor and extensor as well as the difference of these variables between the right and left limbs in youth soccer players. Method: The sample consisted of 45 male youth soccer players for at least a year, aged between 13 and 16 years (14.7+0.86). The athletes underwent an assessment of flexibility of the posterior chain through the sit and reach test on Wells' Bench and an assessment of flexibility of the quadriceps using the Ely's test, with measurement of passive range of motion by goniometry. The peak of muscle strength was measured using a load cell (EMG ${ }^{\circledR}$ System, Brazil). Results: Data analysis showed difference between the values obtained in the Ely's test of right and left leg $(p=0,03)$, which did not happen for flexion strength $(p=0.45)$, extension $(p=0.41)$ and $\mathrm{H}: Q$ ratio $(p=0.40)$ when comparing the two members. It was observed a significant negative correlation between the H:Q ratio and the flexibility of the posterior chain test either for the right side $(r=-0.40 ; p=0.006)$ or left side $(r=-0.50$; $p=0.0004)$. Also a significant positive correlation was observed between quadriceps strength and flexibility of the posterior chain, both for the right $(r=0.31 ; p=0.03)$ and the left side $(r=0.32 ; p=0.02)$. Just for the left side a significant positive correlation was observed when compared the flexor muscle strength with the flexibility of the quadriceps $(r=0.30 ; p=0.03)$. Conclusion: We conclude from this study that the flexibility of the posterior chain may be related to the strength of the antagonists, however, when the two physical qualities were compared in the same muscles, it showed no correlation.
\end{abstract}

Keywords: athletes, sports, isometric contraction.

\section{INTRODUCTION}

Soccer is a widespread sport, being considered the most practiced sport in the world, with approximately 200,000 professionals involved and 240 million practitioners. ${ }^{(1)}$ According to research conducted by the Fédération Internationale de Football Association (FIFA), about 270 million people, including directors, referees and players are involved in a direct way in soccer. ${ }^{(2)}$

The athletes who seek for daily improvements in their incomes for better visibility and preservation of their career, due to the high demand by the coaches plus the volume and load (physical and mental) of the training and the competition system in soccer with many games played during the season, they become more prone to musculoskeletal problems. For this reason, the focus on physical preparation has been much higher nowadays. ${ }^{(3,4)}$
With soccer appreciation, the clubs have found huge difficulty in maintaining athletes with high performance due to high cost, therefore the inclusion and investment in young athletes in the sport are increasing. ${ }^{(5)}$ In our country, the involvement of children with this modality occurs very early and, between 10 and 11 years old, they start participating in championships regulated by the federations. ${ }^{(6)}$

Formerly that modality was characterized as a sport without much contact, in which the art of dribbling was more privileged. But what was known as "football art" is currently undergoing a process of transformation to "football force", resulting in an increased physical and psychological stress of the players, increasing incidences of injuries ${ }^{(7)}$ that occur mainly in the lower limbs and more frequent in knees and ankles. ${ }^{\left({ }^{8}\right)}$ This becomes even more worrying when associated

Corresponding Author: Name: Cristiane Rodrigues Pedroni. Address: Av. Higino Muzzi Filho, 737, CEP 17525-900, Marília, SP; Telephone: +55 (14) 3402-1300. E-mail: pedronicr@marilia.unesp.br

2. Ph.D, Professor of Department of Physical Therapy, School of Philosophy and Sciences - São Paulo State University - UNESP, Marília (SP), Brazil.

Full list of author information is available at the end of the article.

Financial support: This study was financed by the School of Philosophy and Sciences - UNESP.

Submission date 1 October 2016; Acceptance date 18 December 2016; Publication date 29 December 2016 
with young athletes who have an immature musculoskeletal system. ${ }^{(7)}$

The occurrence of injuries in this group may be due to a number of factors, such as the sport practiced, practice time and the level in which it belongs (statewide, national or international), or they may be associated with reduced flexibility, muscular imbalances, deficit in agility and postural changes. $^{(5)}$

Flexibility is characterized as the maximum amplitude of a passive joint movement. ${ }^{(9)}$ Studies have demonstrated that flexibility has a great contribution to the performance of strength training and muscle resistance improving the yield and reducing injuries. ${ }^{(9,10)}$

Many authors describe muscle injury as one of the most frequent in sports. Among them, there are the hamstrings muscle injuries, which occur mostly by imbalance between knee flexor and extensor musculature. ${ }^{(7)}$ Thus, the balance of muscle strength and flexibility between the anterior and posterior thigh is extremely important to prevent injuries. ${ }^{(11,12)}$

In soccer there is great concern in developing strength and power rating especially of extensor muscles, which is the most used concentrically at the time of the kick, resulting in a devaluation in the development of flexibility and muscle strength of the antagonist muscles. ${ }^{(13)}$

Studies of the isokinetic evaluation in athletes showed that there really is an ideal hamstrings:quadriceps $(\mathrm{H}: \mathrm{Q})$ ratio between the knee flexor and extensor musculature, ${ }^{(14,15)}$ and the quadriceps is capable of produce a force three times higher than the hamstrings. ${ }^{(15)}$

Due to lack of national work related to different methods of assessing muscle function in young practitioners of soccer that can offer real information about the muscle function of these individuals and the difficulties encountered by small and medium-sized clubs to perform complex physical assessment in expensive and poorly accessible equipment, we seek through this study, verify the asymmetry index between knee flexors and extensors through a simple, practical and more affordable method.

Thus, the aim of this study was to verify the asymmetry and the correlation between strength and flexibility of the knee flexor and extensor muscles, and the difference of these variables in the right and left limbs of youth soccer players.

\section{METHOD}

This study was conducted in accordance with Resolution 466/12 of the National Health Council (Conselho Nacional de Saúde - CNS) and approved by the Human Research Ethics Committee of the School of Philosophy and Sciences from the Universidade Estadual Paulista Júlio de Mesquita Filho (UNESP) - Marília under protocol 0747/2013.

All volunteers and their parents were informed about the objectives and procedures of the study and signed the Free and Informed Consent.
Were evaluated 45 male players of youth soccer aged between 13 and $16(14.7+0.86)$, belonging to clubs in the city of Marilia-SP, of any nationality or race, regardless of position, soccer practitioners for at least one year and participants of national competitions.

Table 1 shows the anthropometric characteristics of individuals, who participated in the study, with mean and standard deviation.

The non-inclusion criteria in the study were athletes aged under 13 or over 16 , soccer players with less than a year of practice and with some type of musculoskeletal injury in the lower limb.

The study was conducted in the Musculoskeletal Assessment Laboratory the Education and Health Study Center (CEES) of Universidade Estadual Paulista (UNESP) - Marília-SP.

First the volunteers were subjected to a test to evaluate the flexibility of the posterior chain through the Wells' Bench (WB) Terrazul ${ }^{\circledR}$, which the height is $35 \mathrm{~cm}$ and the width is $40 \mathrm{~cm}$ with a standard ruler of $15 \mathrm{~cm}$ in the edge, also known as sit-and-reach test, proposed by Wells and Dillon. ${ }^{(16)}$

The subjects were seated on an exercise mat with their feet in contact with the anterior surface of the bench. After the correct positioning, they were told to push the marker the farthest possible in the ruler of the equipment, performing a single movement of maximum range; the value in centimeters $(\mathrm{cm})$ was recorded immediately by the evaluator. After performing two maximum ranges, was considered the longest distance achieved by the athlete. The test was conducted always by the same evaluator, who remained next to the athlete avoiding that he perform knees flexion or compensation during the test.

To evaluate the flexibility of the quadriceps was performed Ely's test (ET), with measurement of the passive range of motion by goniometry, performed by the same examiner.

The test consisted of the passive flexion of the knee to the maximum range of motion or when there was contact of the heel with the glutes; the athlete remained lying in the prone position on a stretcher with the arms alongside the body. At the moment of the maximum range of passive knee flexion was reached, it was performed goniometry with the goniometer axis on the head of the fibula, the arm fixed on the lateral surface of the thigh toward the greater trochanter of the femur and the arm swing in the fibula toward the lateral malleolus.

TABLE 1. Sample characterization

\begin{tabular}{cc}
\hline VARIABLES & VALUES \\
\hline AGE (years) & $14.73 \pm 0.86$ \\
BODY MASS $(\mathrm{kg})$ & $63.54 \pm 8.35$ \\
STATURE $(\mathrm{m})$ & $1.74 \pm 0.07$ \\
BMI $\left(\mathrm{kg} / \mathrm{m}^{2}\right)$ & $20.93 \pm 2.10$ \\
\hline
\end{tabular}


To measure the peak power (PP) the individuals performed a test on the leg extension with load cells (LC) (System Brasil ${ }^{\circledR}$ EMG) coupled to the equipment cable. The LC remained connected to a digital analog converter (EMG System do Brasi $^{\circledR}$ ). The athletes performed two maximum voluntary isometric contractions of the quadriceps with the right limb and two with the left limb, all lasting five seconds, and then the same was done to evaluate the posterior chain. Before performing each test, the athletes remained resting for at least one minute.

The position chosen for carrying out the isometric contractions was the 60 degrees of knee flexion, both quadriceps and subsequent chain because, according to the literature, in this angulation occurs the production of the maximum strength of knee extensor and flexors muscle. ${ }^{(17,18)}$

During the test period the examiner encouraged the athletes through standardized verbal commands ("c'mon, c'mon, harder, harder"). They were also told to hold on to the support next to the equipment itself, do not talk during the test, do not raise the contralateral leg and/or the hip from the chair in order to avoid compensation.

After each contraction, were recorded the peak power values reached, with resolution of $1 \mathrm{kgf}$ and sensitivity of $0.1 \mathrm{kgf}$, and analyzed using the AqDados ${ }^{\circledR}$ software.

This study used the H:Q ratio, which has been widely used in the literature ${ }^{(15,19)}$, in order to evaluate abnormal imbalance between the reciprocal knee muscle. The $\mathrm{H}: \mathrm{Q}$ ratio was calculated dividing the maximum value of knee flexion by the maximum value of knee extension obtained from isometric contractions. To obtain the percentage the value resulted of the division was multiplied by 100 .

The statistical program used was Graphpad Instat ${ }^{\circledR}$ and the Kolmogorov-Smirnov test to verify the normality of the data. The unpaired t test was used to verify the difference between the values tested in the right and left limbs and the Pearson test to evaluate the correlation between variables, considering $0.49<R<0.69$ moderate values and $R \geq 0,7$ strong values, and values with $\mathrm{p}<0.05$ were considered significant.

\section{RESULTS}

Among the 45 participating athletes, only 12 had the left leg as dominant (26.6\%) and 33 had the right leg as dominant (73.3\%).

In relation to the flexibility test of the posterior chain through the Wells' Bench, were found average values of $28 \pm 6.47 \mathrm{~cm}$ for the evaluated group. Table 2 shows the average values found in strength tests, flexibility of the quadriceps and $\mathrm{H}: \mathrm{Q}$ ratio. Values obtained in the Ely's test of the right and left leg were significantly different $(p=0.03)$, which was not observed in flexion $(p=0.45)$ and extension $(p=0.41)$ strength values and $H: Q$ ratio $(p=0.40)$ when comparing the two limbs.

The table 3 shows the values of correlation between $\mathrm{H}: \mathrm{Q}$ ratio, flexibility and peak power. Was observed a significant negative correlation between the $\mathrm{H}: \mathrm{Q}$ ratios and the flexibility test of the posterior chain, which means that the smaller the ratio, meaning the greater quadriceps force on the flexors, the greater the flexibility of the posterior thigh. Also in relation to the flexibility of the posterior chain, there was a significant positive correlation when related to the quadriceps force in both lower limbs, indicating that an increase in quadriceps force was directly related to an increase in the flexibility of the posterior chain. In addition, was observed a significant positive correlation between the knee flexor strength and the flexibility of the quadriceps in the left lower limb.

\section{DISCUSSION}

The aim of this study was to verify the asymmetry and the correlation between strength and flexibility of the knee flexor and extensor muscles, and the difference of these variables between the right and left limbs in youth soccer players.

There was a statistically significant difference in the values obtained in Ely's test of right and left leg, i.e., the flexibility of the quadriceps of the right leg was higher than the left leg. In $73.3 \%$ of the subjects, the right leg was the dominant,

TABLE 2. Average values of flexibility of the quadriceps, peak power of the muscle (kgf) and asymmetry in youth soccer players $(n=45)$

\begin{tabular}{lcc}
\hline & Right Limb & Left Limb \\
\hline ELY'S (degrees) & $144.15 \pm 5.4$ & $142.24 \pm 5.56^{*}$ \\
EXTENSION (Kgf) & $64.13 \pm 16.41$ & $62.71 \pm 16.18$ \\
FLEXION (Kgf) & $36.08 \pm 8.97$ & $36.15 \pm 8.75$ \\
H:Q RATIO (\%) & $57.7 \pm 13.48$ & $58.9 \pm 11.05$ \\
\hline
\end{tabular}

*= significant difference between the right and left sides; $p<0.05$

TABLE 3. Correlation values between the asymmetry, flexibility and peak power indexes in youth soccer players $(n=45)$.

\begin{tabular}{lll}
\hline Correlation & \multicolumn{1}{c}{$\mathbf{r}$} & \multicolumn{1}{c}{$\mathbf{P}$} \\
\hline H:Q R X WB & -0.40 & $0.006^{*}$ \\
H:Q L X WB & -0.50 & $0.0004^{*}$ \\
H:Q R X ET R & 0.02 & 0.85 \\
H:Q L X ET L & 0.16 & 0.28 \\
PPRE X WB & 0.31 & $0.03^{*}$ \\
PPLE X WB & 0.32 & $0.02^{*}$ \\
PPRF X WB & 0.04 & 0.78 \\
PPLF X WB & -0.06 & 0.68 \\
PPRE X ET R & 0.21 & 0.16 \\
PPLE X ET L & 0.15 & 0.31 \\
PPRF X ET R & 0.23 & 0.11 \\
PPLF X ET L & 0.30 & $0.03^{*}$
\end{tabular}

$\mathrm{H}: \mathrm{Q}$ R - hamstrings/quadriceps ratio of the right leg; WB - Well's Bench; H:Q L hamstrings/quadriceps ratio of the left leg; ET R - Ely's test of the right leg; ET L - Ely's test of the left leg; PPRE - peak power of right extension; PPLE - peak power of left extension; PPRF - peak power of right flexion; PPLF - peak power of left flexion; Pearson Correlation, ${ }^{*} p<0.05$. 
we can observe that the flexibility of the quadriceps of the non-dominant leg proved to be reduced in relation to the leg used to kick. The same was observed in a study conducted by Daneshjoo et al. ${ }^{(12)}$ with professional and youth soccer players (age: $18.9 \pm 1.4$ ), being verified more flexibility of the posterior chain in the dominant leg than in the non-dominant leg through the straight leg raise test; which may increase the incidence of injuries. This difference of flexibility between both legs can be explained by the preference of using dominant leg to kick, in which the non-dominant leg ends assuming mainly postural support function. ${ }^{(12,20)}$ Another explanation may be that the repeated use of one of the legs to kick can be compared to a dynamic stretching ${ }^{(12)}$, justifying the increased flexibility of the dominant side.

In this study, the athletes had a $\mathrm{H}: \mathrm{Q}$ ratio averaging $57.78 \%+13.48$ to the right leg and $58.89 \%+11.05$ to the left leg. The percentages obtained in our study are similar to those reported in the literature ${ }^{(15)}$, indicating an ideal $\mathrm{H}: \mathrm{Q}$ ratio around 60 and $70 \%$ and the force produced by the extensor muscles tend to be three times greater than the flexor muscles.

Our results are similar to those obtained by Pinto and Arruda $^{(13)}$ in which the mean of $\mathrm{H}: \mathrm{Q}$ ratio was $57.7 \%$ and Leonardi et al. ${ }^{(21)}$ who obtained $\mathrm{H}: \mathrm{Q}$ ratios to the right and left leg respectively 59.81 and $59.44 \%$ for soccer field players and $60.47 \%$ and $54.80 \%$ for indoor soccer players; But this study was conducted with professional soccer players, older, with more workload and consequently greater physical development.

The literature suggests that in most studies, the values of the $\mathrm{H}: \mathrm{Q}$ ratio are obtained from isokinetic assessments ${ }^{(12,15,21)}$ and difficultly are found studies that used this assessment to obtain the values of $\mathrm{H}: \mathrm{Q}$ ratio. ${ }^{(19)}$

Despite the lack of studies using the isometric contractions as evaluation method, high relations between isometric and isokinetic strength in both quadriceps and its antagonist have been observed. ${ }^{(22)}$ Besides the different forms of evaluation, the asymmetry indexes may vary according to the type of sport practiced. ${ }^{(23)}$

Because of the difficult access to sophisticated equipment, new, simple and accessible evaluation methods have been used, but there is a need for new studies to support the use of these tests in clinical practice. This methodology would allow through alternative methods to select the individuals who needed a more complex and detailed assessment in more expensive equipment, such as the isokinetic dynamometer. Such methods should be easy to use, applicable in a short period and mainly provide truthful information about the muscle function that will be evaluated. ${ }^{(24)}$

The literature suggests that the value of a muscle group non-affected can be considered normal, as long as it is equal or show difference of up to $20 \%$ when compared to the contralateral muscle group in sports activities. Values below $60 \%$ have been associated with distension of the hamstring. ${ }^{(21)}$
When there are significant imbalances between reciprocal musculature, there is a predisposition to injuries in joint or musculatures. ${ }^{(23,25)}$ In the case of the adequacy of the $\mathrm{H}: \mathrm{Q}$ ratio closer to normal, a period of training involving strengthening of hamstrings is extremely important. ${ }^{(26)}$

An important finding in our study was the presence of significant positive correlation between the strength of the quadriceps with the flexibility of the posterior chain, both to the right and to the left as well as the strength of the left flexors with the flexibility of the quadriceps.

There is much controversy about the relation between strength and flexibility of the muscle. Several studies conducted in order to relate these two physical abilities have shown that there is a positive correlation between them, i.e., the power gain does not imply increased in flexibility or vice versa, suggesting independence among them, but most studies related the two qualities in the same muscle. ${ }^{(27,28)}$

In our study we observed relation between muscular strength and flexibility when compared to antagonists musculatures, but when compared muscle strength with the flexibility of the same muscles significant correlation was observed, demonstrating that the two may be independent qualities.

However observing the two physical qualities between agonist and antagonist, it was found that they may be related, and the training can alter one over the other. Studies have shown that the association between stretching exercises with muscle strength training is capable to promote increase in muscle strength of the antagonist muscles. ${ }^{(29,30)}$ Thus, coaches, trainers and professionals who work in sports should pay attention to the two physical qualities. It is important the development of both strength and flexibility in a supervised and controlled manner, so that players can keep an expected level of balance between the two and, thus, increase their sports performance.

Based on this study, professionals working in sport can pay attention to possible physical changes in the balance of muscle strength and in the flexibility of lower limbs of their athletes from simple and affordable assessments. Thus, an individualized and specific work can be done, preventing the chances of injury, given that most of the time they occur through muscular imbalances and reduced flexibility. Furthermore, physiotherapists will be able to perform studies or clinical protocols within the sports physical therapy for best performance of the athletes on the field.

Given the lack of studies in the literature correlating the muscle strength and flexibility between antagonistic musculatures and the growing number of young professional or non-professional athletes in soccer, there is a need to develop further studies as this one, but in longitudinal studies associating the $\mathrm{H}: \mathrm{Q}$ ratios and/or flexibility with incidences of sports injuries. 
This study showed limitations regarding the method used to evaluate flexibility of the posterior chain because of the influence of the gastrocnemius muscle and for not specifically assess the flexibility of the hamstrings. Likewise, there are limitations to evaluate the flexibility of the quadriceps through the Ely's test because of the possible influence that the increased muscle mass of the gluteus and the hamstrings can provide during the evaluation.

\section{CONCLUSION}

We conclude from this study that the flexibility of the posterior chain may be related to the strength of the antagonists, however, when the two physical qualities were compared in the same muscles showed no correlation and can be considered independent qualities in this situation.

\section{AUTHOR'S CONTRIBUTIONS}

Cursino MP - Data collection and preparation of the manuscript; Marques AEZS- Preparation of the manuscript; Quatrochi- Data collection and analysis; Faganello-Navega FR-Co-advisor; Pedroni CR-Advisor.

\section{CONFLICT OF INTEREST}

The authors declare that they have no conflicts of interest.

\section{AUTHOR DETAILS}

1. Physiotherapist, Department of Physical Education, Biosciences Institute, São Paulo State University- UNESP, Rio Claro (SP), Brazil. 3. Physiotherapist, specialist in Applied Rehabilitation of Child Neurology, State University of Campinas (UNICAMP), Campinas (SP), Brazil. 4. Ph.D, Professor of Department of Physical Education, Biosciences Institute, São Paulo State University- UNESP, Rio Claro, São Paulo, Brazil

\section{REFERENCES}

1- Dvorak J, Junge A. Football injuries and physical symptoms: a review of the literature. Am J Sports Med. 2000;28:3-9.

2- FIFA. Regras do jogo. Zurich, Suiça 2001.

3- Silva LM, Rubio K. Superação no esporte: limites individuais ou sociais? Revista Portuguesa de Ciências do Desporto. 2003;3(3):69-76.

4- McCall A, Davison M, Andersen TE, Beasley I, Bizzini M, Dupont G et al. Injury prevention strategies at the FIFA 2014 World Cup: perceptions and practices of the physicians from the 32 participating national teams. British Journal of Sports Medicine. 2015;49(9):603-608. doi:10.1136/ bjsports-2015-094747.

5- Arena SS, Carazzato JG. A relação entre o acompanhamento médico e a incidência de lesões esportivas em atletas jovens de São Paulo. Rev bras med esporte. 2007;13 (1):217-21.

6- Barbieri FA, Benites LC, Machado, AA. Especialização precoce: algumas implicações relacionadas ao futebol e futsal. Especialização esportiva precoce: perspectivas atuais da psicologia do esporte. 2007;207-225.

7- Bertolini FRG, Mello LG, Otowicz I, Ruaro AJ, Aratani CM, Fonseca S. Incidência de lesões no futebol em atletas jovens e a importância da fisioterapia preventiva. Fisioterapia em Movimento. 2003;16(3):71-77.

8- Mafulli N, Caine DJ. Epidemiology of Pediatric Sports Injuries: Team Sports Medicine and Sport Science. 2005;49:140-169.

9- Farinatti PTV. Flexibilidade e esporte: uma revisão da literatura. Revista Paulista de Educação Física. 2000;14(1):85-96.

10- Santos CF, Domingues CA. Avaliação pré e pós mobilização neural para ganho da ADM em flexão do quadril por meio do alongamento dos isquiotibiais. Revista ConScientiae Saúde. 2008;7(4):487-495.
11- Silva SRP, Pedrinelli A, Teixeira AAA, Angelini JF, Facci E, Galotti R, et al. Aspectos descritivos da avaliação funcional de jogadores de futebol. Revista Brasileira de Ortopedia. 2002;37:205-210.

12- Daneshjoo A, Rahnama N, Mokhtar AH, Yusof A. Bilateral and Unilateral Asymmetries of Isokinetic Strength and Flexibility in Male Young Professional Soccer Players. Journal of human kinetics. 2013;36(1):45-53.

13- Araújo JD, Silva RR, Carnevali Junior LC, Paula Lima WA. Influência do fortalecimento e alongamento muscular no desequilibrio entre músculos flexores e extensores do joelho em atletas de futebol de campo. Brazilian Journal of Biomotricity. 2009;3(4):339-350.

14- Magalhães J, Oliveira J, Ascensão A, Soares J. Concentric quadriceps and hamstring isokinetic strength in volleyball and soccer players. Journal of Sports Medicine and Physical Fitness. 2004;44:119-125.

15- Pinto SS, Arruda AC. Avaliação isocinética de flexores e extensores de joelho em atletas de futebol profissional. Fisioterapia em Movimento. 2001;13:37-43.

16- Wells KF, Dillon EK. The sit and reach: a test of back and leg flexibility. Research Quarterly for Exercise and Sport, Washington. 1952;23:115-118.

17- Correa CS et al. Análise da força isométrica máxima e do sinal de EMG em exercícios para os membros inferiores. Rev. bras. cineantropom. desempenho hum. 2011;13(6).

18- Pincivero DM, Campy RM, Salfetnikov Y, Coelho AJ. Knee extensor torque and quadríceps femoris EMG during percentually-guided isometric contractions, Journal of Eletromyography and Kinesiology. 2003;13:159167.

19- Beutler A, de la Motte S, Marshall S, Padua D, Boden B. Muscle strength and qualitatice jump-landing differences in male and female military cadets: The jump- ACL study. J Sports Sci Med. 2009;8:663-671.

20- Fousekis K, Tsepis E, Vagenas G. Lower limb strength in professional soccer players: profile, asymmetry, and training age. Sports Sci Med. 2010;9:364373.

21- Leonardi ABA, Martinelli MO, Duarte Junior A. Existe diferença nos testes de força da dinamometria isocinética entre jogadores profissionais de futebol de campo e de futebol de salão? Rev. bras. ortop. 2012;47(3).

22- Lord J, Aitkens S, McCrory M, Bernauer E. Isometric and isokinetic measurement of hamstring and quadriceps strength. Arch Phys Med Rehab. 1992;73:324-33.

23- Alter M. Science of flexibility. Second edition. Human Kinetics Publishers, USA 2004;221-226.

24- D’Alessandro RL, Silveira EAP, Anjos MTS, Silva AA, Fonseca ST. Análise da associação entre a dinamometria isocinética da articulação do joelho e o salto horizontal unipodal, hop test, em atletas de voleibol. Rev Bras Med Esporte 2005; 11(5).

25- Gabbe B, Bransonb R, Bennell K. A pilot randomised controlled trial of eccen- tric exercise to prevent hamstring injuries in community-level Australian Football. J Sci Med Sport. 2006;9:103-109.

26- Holcomb R, Rubley M, Lee H, Guadagnoli M. Effect of hamstringemphasized resistance training on hamstring:quadriceps strength ratios. J Strength Cond Res. 2007;21:41-47.

27- Higajo N, Andrade DR, Pereira MHN. Relação entre a flexibilidade e a força dos membros inferiores em voleibolistas de alto nível. Revista Brasileira de Ciência e Movimento. 2008;5(3):7-12,

28- Nóbrega AC, Paula KC, Carvalho AC. Interaction between resistance training and flexibility training in healthy young adults. J Strength Cond Res. 2005;19:842-6

29- Batista LH, Camargo PR, Oishi J, Salvini TF. Effects of an active eccentric stretching of the knee flexor muscles on range of motion and torque. Rev Bras. Fisioter. 2008;12:176-82.

30- Seynnes OR, De Boer M, Narici MV. Early skeletal muscle hypertrophy and architectural changes in response to high-intensity resistance training. J Appl Physiol. 2007;102:368-73. 